\title{
$\beta$ Spectrin Kissimmee: A Spectrin Variant Associated with Autosomal Dominant Hereditary Spherocytosis and Defective Binding to Protein 4.1
}

\author{
Pamela S. Becker, ${ }^{*}$ William T. Tse, * Samuel E. Lux, ${ }^{\star}$ and Bernard G. Forget ${ }^{*}$ \\ *Hematology Section, Department of Internal Medicine, Yale University School of Medicine, New Haven, Connecticut 06510; \\ and ${ }^{\ddagger}$ Division of Hematology-Oncology, Children's Hospital and Dana-Farber Cancer Institute, Boston, Massachusetts 02115
}

\begin{abstract}
We analyzed the DNA sequence of the cDNA encoding the $\mathrm{NH}_{2}$ terminal region of $\beta$ spectrin from members of a kindred with autosomal dominant hereditary spherocytosis associated with defective protein 4.1 binding. We found a point mutation at codon 202 within the 272 amino acid $\mathrm{NH}_{2}$-terminal region of $\beta$ spectrin. TGG was changed to CGG, resulting in the replacement of tryptophan by arginine. The base change eliminates a normally occurring PvuII restriction site and creates a new MspI site. This finding enabled rapid detection or exclusion of the mutation at the DNA level among the family members, including one member for whom this analysis was performed prenatally. The mutation was found only in the affected family members and occurred as a de novo mutation in the proband. It has not been found in 20 other kindreds. The recombinant peptide derived from the normal cDNA retains the capacity to sediment with protein 4.1 and $F$-actin. The mutant peptide spontaneously degrades. This variant represents both the first point mutation and the first $\beta$ spectrin mutation demonstrated in autosomal dominant hereditary spherocytosis. Furthermore, the mutation is located within a conserved sequence among spectrinlike proteins and may define an amino acid critical for protein 4.1 binding activity. (J. Clin. Invest. 1993. 92:612-616.) Key words: congenital hemolytic anemia $\bullet$ cytoskeleton $\bullet$ polymerase chain reaction $\bullet$ erythrocyte membrane $\bullet$ acanthocytes
\end{abstract}

\section{Introduction}

Hereditary spherocytosis (HS) ${ }^{1}$ is a clinically and genetically heterogeneous disorder of the red blood cell characterized by increased osmotic fragility and spheroidal shape. There is a classical, autosomal dominant type and a more severe, recessively inherited form (for review, see reference 1 ). The bio-

A portion of this work was presented at the 32 nd annual meeting of the American Society of Hematology, December 1990, and published in abstract form (1990. Blood. [Suppl. 1]76:25a).

Address reprint requests to Dr. Pamela Becker, Division of Hematology-Oncology, Department of Medicine, University of Massachusetts Medical Center, 55 Lake Avenue North, Worcester, MA 01655. Dr. Tse's present address is Department of Pathology, Stanford University Medical Center, Stanford, CA 94305.

Received for publication 3 November 1992 and in revised form 11 March 1993.

1. Abbreviations used in this paper: GST, glutathione-S-transferase; HE, hereditary elliptocytosis; HS, hereditary spherocytosis; IPTG, isopropyl $\beta$-D-thiogalactopyranoside; RT, reverse transcription.

J. Clin. Invest.

(c) The American Society for Clinical Investigation, Inc.

$0021-9738 / 93 / 08 / 0612 / 05 \$ 2.00$

Volume 92, August 1993, 612-616 chemical defects in these disorders are related to abnormalities in the red blood cell membrane proteins. Deficiency of the erythrocyte membrane skeleton protein, spectrin, has been demonstrated in patients with recessive HS (2) and a majority of patients with autosomal dominant $\mathrm{HS}$ (3), and the degree of deficiency appears to correlate with clinical severity (4).

There is asymmetry in the relative synthetic rates of $\alpha$ and $\beta$ spectrin, in that the synthesis of $\alpha$ spectrin is threefold in excess of $\beta$ spectrin synthesis in murine, rat, and human erythroblasts (5-7). Spectrin assembly on the membrane appears to be rate limited by the $\beta$ chain. Therefore one could predict that defects in $\beta$ spectrin would be manifest in the heterozygous state and result in dominantly inherited conditions. In contrast, defects in $\alpha$ spectrin may not be manifest until the homozygous state is reached, since the $\alpha$ chains are synthesized in excess to the $\beta$.

Three kindreds with autosomal dominant HS in which the spectrin is defective in its ability to bind protein $4.1(8,9)$ have been previously described. In one of the kindreds, previous studies demonstrated that approximately $40 \%$ of the spectrin was unable to bind protein 4.1 (9) and that there was abnormal chymotryptic digestion of the isolated $\beta$ spectrin in individuals from this kindred (10). There was also spectrin deficiency to $80 \%$ of the normal quantity (10), a level which is comparable with that of the autosomal dominant type of HS. The one unusual feature noted in this kindred was prominent acanthocytosis, even before splenectomy, among the affected individuals $(9,10)$.

By electron microscopy, other investigators (11) had localized the protein 4.1 binding site to the end of the spectrin dimer opposite the self-association site, although the specific chain could not be identified. In addition, our prior investigation using photoaffinity, radiolabel-transfer cross-linking demonstrated that the binding site for protein 4.1 was within the general region of the $\mathrm{NH}_{2}$-terminal domain of $\beta$ spectrin (12). Because both the abnormal chymotryptic digestion data indicated an abnormality of $\beta$ spectrin and the cross-linking studies suggested that the $\mathrm{NH}_{2}$-terminal region of $\beta$ spectrin contained the binding site for protein 4.1 , we analyzed this region of $\beta$ spectrin in an effort to define the molecular defect in this family with HS. We now report the identification, in the affected members of this kindred, of a point mutation in the gene encoding the $\mathrm{NH}_{2}$-terminal region of $\beta$ spectrin. By defining a potentially critical amino acid residue for the protein 4.1 binding function, this mutation improves considerably our localization of the presumed binding site on spectrin for protein 4.1. This molecular defect has been designated $\beta$ spectrin Kissimmee based on the location of the residence of the affected kindred.

\section{Methods}

Polymorphism linkage analysis. A $\beta$ spectrin RFLP was detected by hybridizing Southern blots of HindIII digested genomic DNA with a 3' $\beta$ spectrin cDNA probe $(\beta 28)(13)$. 
PCR primers. The sequences of the forward and reverse PCR primers used for amplification of the $5^{\prime}$ end of the $\beta$ spectrin cDNA are N $\beta 1$, 5'-AGGGCAGGGATCCTTCCATG-3' and N $\beta 2$ (AS), 5'-GCTCTAGCTTCTCCTGCCGA-3', respectively. $\mathrm{N} \beta \mathrm{I}$ is located $5^{\prime}$ to the initiator methionine and contains a BamH1 site (underlined) in the native sequence. $\mathrm{N} \beta 2$ (AS) is located within spectrin repeat 2 (Fig. 1). These primers flank a 1.3-kb segment of the cDNA. The sequences of the forward and reverse PCR primers used for amplification of a segment of a portion of the $5^{\prime}$ end of the beta spectrin gene are $\mathrm{N} \beta 5$, 5'-CAGATTCAGGACATTGTGGT-3' and N $\beta 7$ (AS), 5'-GTCGAGGAGCGGGATGATGC-3', respectively. These primers flank a 1.1-kb segment of the gene that contains three exons and two introns.

Reverse transcription (RT) and amplification of $c D N A$. RNA was isolated from reticulocytes by ammonium chloride lysis of peripheral blood, and $\beta$ spectrin cDNA was obtained by RT as described $(14,15)$, utilizing the antisense primer $\mathrm{N} \beta 2$ (AS). For the PCR amplification of the RT product, 40 cycles of amplification were performed using an automated DNA Thermal Cycler (Perkin Elmer Corp., Norwalk, CT) with the following conditions: melting, $1.5 \mathrm{~min}$ at $94^{\circ} \mathrm{C}$; annealing, 2 min at $55^{\circ} \mathrm{C}$; polymerizing, $3 \min$ at $72^{\circ} \mathrm{C}$.

Nucleotide sequencing. Primers $\mathrm{N} \beta 1$ and $\mathrm{N} \beta 2(\mathrm{AS})$ were utilized for PCR. The BamHI and SacI sites used for subcloning were located within the native sequence. The PCR product was subcloned into pGEM 7 vector (Promega Biotec, Madison, WI) and 13 separate subclones were sequenced by the dideoxynucleotide method (16).

Amplification of genomic DNA and restriction digests. Genomic DNA was obtained by standard procedures from peripheral blood leukocytes from the various members of this kindred, an unrelated control, and at least one affected member of 15 unrelated kindreds with autosomal dominant HS and 5 unrelated kindreds with nondominant HS. In addition, genomic DNA was obtained from an affected individual from each of two kindreds reported by Goodman and co-workers (8) to have defective binding of protein 4.1 by spectrin. One sample of genomic DNA was isolated by standard means from cultured fetal amniocytes. The amniocytes were excess cells obtained after standard chromosome analysis for prenatal exclusion of Down's syndrome in a fetus ( member III-4 of the kindred) of the 39-yr-old proband ( member II-2 of the kindred). The PCR amplification of the genomic DNA was performed using the $\mathrm{N} \beta 5$ and $\mathrm{N} \beta 7$ (AS) primers and the DNA Thermal Cycler with the following conditions: 30 cycles, melting, $1.5 \mathrm{~min}$ at $94^{\circ} \mathrm{C}$; annealing, $2 \mathrm{~min}$ at $65^{\circ} \mathrm{C}$; polymerizing, $3 \mathrm{~min}$ at $72^{\circ} \mathrm{C}$. The amplified DNA was then digested with PvulI or MspI, separated by agarose gel electrophoresis and visualized by ultraviolet transillumination after staining with ethidium bromide.

Allele-specific oligomer hybridization. There was one nucleotide substitution identified in only 2 of the 13 subclones. In order to exclude this as a polymorphism linked to the mutation or the mutation itself, allele-specific oligomer hybridization was performed as described (17) and modified (18). The duplicate slot blots of the PCR amplified genomic DNA samples were each hybridized with one of the ${ }^{32} \mathrm{P}$-labeled oligomers, 5'-GCAGGCTACCCTCATGTTA-3' and 5'-GCAGGC-

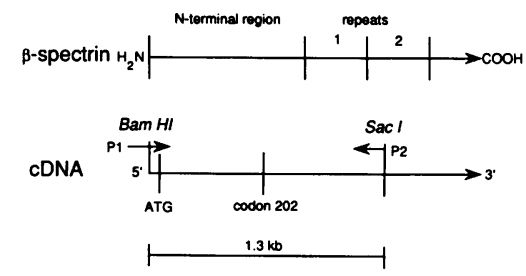

Figure 1. Protein and cDNA structure for the $\mathrm{NH}_{2}$-terminal region of $\beta$ spectrin. The first line represents the $\beta$ spectrin protein and the second line represents the cDNA for $\beta$ spectrin. The $\mathrm{NH}_{2}$-terminal re-

gion consists of 272 amino acids (23), after which follow the spectrin repeats. The arrows labeled $P 1$ and $P 2$ indicate the position of the primers used for PCR amplification of this region of cDNA. They correspond to $\mathrm{N} \beta 1$ and $\mathrm{N} \beta 2$ in Methods. The BamHI and SacI sites exist within the native sequence. The PCR amplified product is 1.3 $\mathrm{kb}$.
TACICTCATGTTA-3' (normal and proposed mutant, respectively, with the nucleotide difference underlined).

Bacterial expression of recombinant proteins. One of the normal and one of the mutant subclones were selected for expression in $E$. coli as fusions with glutathione-S-transferase (GST) (19). PCR was performed using the pGEM 7 plasmids containing the cDNA inserts and new primers, $\mathrm{N} \beta 1 \mathrm{~A}$ and $\mathrm{N} \beta 2 \mathrm{~A}(\mathrm{AS})$, 5'-GCGGATCCAGCCTGCTGACATGACATCATC-3' and 5'-GCGAATTCGAGCTCATTTCTCAGGGCCA-3', with linkers containing BamHI and EcoRI restriction sites (underlined), respectively. The PCR product was subcloned into pGEX $3 X(19)$. Because of difficulty in obtaining a stable recombinant peptide in appreciable quantity, even after cleavage with activated Factor Xa (20), a nonsense codon linker designated NheI*, d(CTAGCTAGCTAG) (New England Biolabs, Inc., Beverly, MA) was inserted at a native Nhel site just after the start of the first spectrin repeat, thereby shortening the peptide. E. coli strain DH5 $\alpha$ (Bethesda Research Laboratories, Gaithersburg, MD) were transformed with the recombinant pGEX plasmid, and expression of the recombinant protein was induced with isopropyl- $\beta$-D-thiogalactopyranoside (IPTG) as described (19). The bacteria were lysed with sonication and $1 \%$ Triton $\mathrm{X}-100$. The lysis buffer ( $20 \mathrm{mM}$ Na phosphate, $150 \mathrm{mM} \mathrm{NaCl}, \mathrm{pH} 7.4$ ) contained the protease inhibitors PMSF $(1 \mathrm{mM})$, leupeptin $(10 \mu \mathrm{g} /$ $\mathrm{ml}$ ), pepstatin $(5 \mu \mathrm{g} / \mathrm{ml})$, benzamidine $(200 \mu \mathrm{g} / \mathrm{ml})$, and aprotinin ( 5 $\mu \mathrm{g} / \mathrm{ml}$ ). The recombinant protein was recovered from the supernatant after centrifugation by affinity chromatography with glutathione agarose beads (Sigma Chemical Co., St. Louis, MO). The beads bearing the GST-protein conjugate were washed multiple times with the above lysis buffer to remove contaminating proteins. The free recombinant protein was eluted from the agarose beads with $5 \mathrm{mM}$ glutathione in 50 mM Tris, pH 8.

Protein functional binding assays. The purified $64-\mathrm{kD}$ recombinant GST-spectrin peptide was incubated with protein 4.1 and actin to assay for binding capability. The mixtures contained 1-10 $\mu \mathrm{g}$ peptide, $15 \mu \mathrm{g}$ F-actin, and $10 \mu \mathrm{g}$ protein 4.1 , in a total volume of 80-90 $\mu 15 \mathrm{mM} \mathrm{Na}$ phosphate, $10 \mathrm{mM}$ Tris, $130 \mathrm{mM} \mathrm{KCl}, 20 \mathrm{mM} \mathrm{NaCl}, 2 \mathrm{mM} \mathrm{MgCl}$, and $0.2 \mathrm{mM}$ ATP. Control samples included binary mixtures of peptide and actin, peptide and protein 4.1 , protein 4.1 and actin, as well as individual samples of peptide, protein 4.1 , or actin alone. The samples were maintained at room temperature for $90 \mathrm{~min}$, then centrifuged in an airfuge (Beckman Instruments, Inc., Palo Alto, CA) at 18 psi for 15 min. The supernatants and pellets were analyzed by SDS-PAGE (21). The amount of peptide in the pellets was quantified by elution of the band with $25 \%$ pyridine. The $A_{605}$ of the eluted dye samples was compared with a standard curve constructed from the $A_{605}$ values for eluted bands from gels run on known microgram quantities of the same protein.

Case report. The clinical course and hematological features of the affected members of this kindred have been previously reported (9). In brief, the proband and two of her children are affected with moderate hemolytic anemia and increased osmotic fragility of erythrocytes. The affected individuals all required splenectomy in childhood, the two daughters of the proband were severely jaundiced at birth, and one underwent exchange transfusion. The father (I-2) of the proband (II-2) had previously been reported as an affected individual as a result of a one-point assay of spectrin-protein 4.1 binding at a single concentration (9). In fact, however, he has less than $10 \%$ spherocytes on peripheral smear, a normal hemoglobin, and normal incubated osmotic fragility test, and is thus unaffected by spherocytosis. Nonpaternity was excluded by RFLP analysis (I. G. Laboratories, Inc., Framingham, MA). The probability of paternity was 0.99887 relative to a random man in the North American Caucasian population. The other members of the kindred are clinically unaffected.

\section{Results}

Our previous studies (10) of this kindred by proteolytic digestion of the individual spectrin chains had suggested a defect in $\beta$ spectrin. We now attempted confirmation of linkage of the 
defect to $\beta$ spectrin by RFLP analysis using the HindIII polymorphism at the $3^{\prime}$ end of the $\beta$ spectrin gene (13). Such analysis did not exclude linkage of the defect in this kindred to $\beta$ spectrin, but because of the small number of family members, the result was not statistically significant (data not shown).

We had also previously shown that the binding site for protein 4.1 was located within the $\mathrm{NH}_{2}$-terminal region of $\beta$ spectrin before the beginning of the spectrin repeat structure (12). We therefore decided to amplify this region of the $\beta$ spectrin cDNA. RNA isolated from peripheral blood reticulocytes of the affected proband was examined by nucleotide sequencing after reverse transcription, PCR, and subcloning. Sequencing of 13 subclones revealed a single base substitution in codon 202 resulting in a change from TGG to CGG in 7 of the clones (Fig. 2 ). This substitution causes an amino acid replacement of tryptophan by arginine. The mutation abolishes a PvuII restriction site (CAGCTG to CAGCCG) and creates a new MspI site

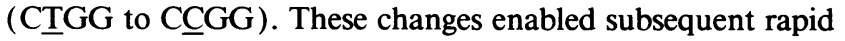
detection in affected and unaffected family members by restriction analysis of PCR amplified genomic DNA. The occurrence of the mutation in about half of the sublones analyzed is consistent with the heterozygous status of the proband.

The only other nucleotide change found in more than one subclone was a change from TGC to CGC at codon 87 , identified in 2 of the 13 subclones. However, allele-specific oligomer hybridization revealed that this change was not present in the affected individuals' genomic DNA (data not shown). Thus, this change was attributed to an error of the Taq polymerase used for PCR.

Restriction enzyme digestion with PvulI (Fig. 3) of a 1.1-kb fragment of genomic DNA produced by PCR amplification normally yields products of 500 and $350 \mathrm{bp}$. In the three affected individuals, an uncleaved product of $850 \mathrm{bp}$ is also generated (Fig. 3), indicating the presence of the mutation. The affected individuals demonstrated both patterns because they are heterozygous for the mutation, consistent with the dominant nature of the disorder. Neither of the grandparents have the uncleaved product, suggesting that the mutation had occurred spontaneously in the proband and was transmitted to two of her four children. This uncleaved product was also not observed in the unaffected family members, an unrelated control without hemolytic anemia, and one member from each of the other two known HS kindreds (8) with a defect in the binding of protein 4.1 by spectrin (Fig. 3 ). In addition, no such product was observed in family members from 15 other unrelated kindreds with autosomal dominant HS or 5 unrelated kindreds with nondominant HS (data not shown).

The mutation could be confirmed by restriction enzyme digestion of PCR amplified genomic DNA with MspI. MspI digestion of the same $1.1-\mathrm{kb}$ fragment (Fig. 4) normally pro-
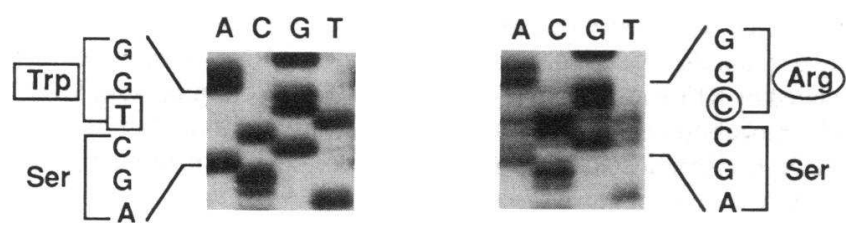

Figure 2. Nucleotide sequence of the $\beta$ spectrin cDNA. The 5' coding region for $\beta$ spectrin from the heterozygous proband was amplified by PCR, subcloned, and sequenced. A point mutation was detected in 7 of 13 subclones that change a codon for tryptophan, TGG, to one for arginine, CGG.

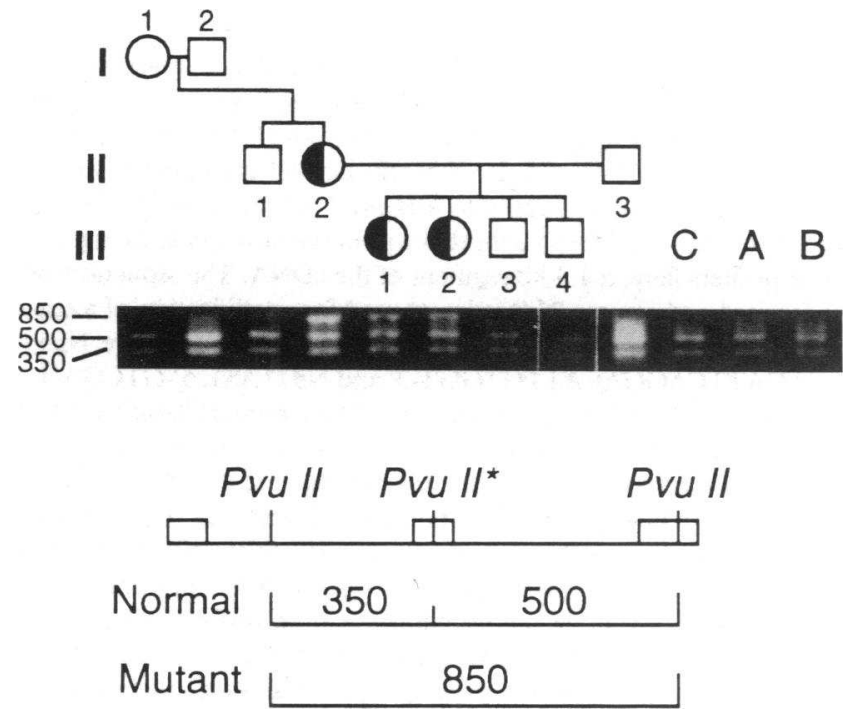

Figure 3. Restriction enzyme digestion with PvulI. Genomic DNA was amplified from family members by PCR using the primers N $\beta 5$ and $\mathrm{N} \beta 7$ (AS). The Roman numerals I, II, and III indicate the generations. The Arabic numerals identify the family members in each generation. $C$ indicates a sample from an unrelated control; $A$ and $B$ indicate samples from the two kindreds described by Goodman and co-workers $(8)$ to possess the same functional defect of spectrin. The open boxes denote the exons. The products produced by PvuII digestion are 500 and $350 \mathrm{bp}$ in the case of the normal individuals. The PvulI site identified by the asterisk indicates the site that is abolished in the affected individuals and results in the creation of a product of $850 \mathrm{bp}$. Because the affected individuals are heterozygous, all three bands are seen in the patients, but only two in the unaffected family members and control. III,4 represents the digest of the sample of fetal genomic DNA.

duces products of 650 and $400 \mathrm{bp}$. Because the mutation creates a new MspI site, an additional product of $600 \mathrm{bp}$ is observed in the three affected family members and not in unaffected individuals.

Moreover, the restriction digestion with PvuII was employed to analyze genomic DNA from cultured amniocytes obtained during the proband's fourth pregnancy. The pattern was that of the unaffected individuals, with 500 and $350 \mathrm{bp}$ fragments (Fig. 3; III-4). This analysis represents the first reported prenatal exclusion of HS.

To demonstrate the consequence of this mutation on protein function, we ligated fragments of this region of $\beta$ spectrin cDNA into pGEX plasmids. The $64-\mathrm{kD}$ recombinant normal and mutant peptides were produced in $E$. coli following induction with IPTG. However, after glutathione agarose affinity chromatography, there was rapid degradation of the mutant recombinant peptide to a 32-kD polypeptide (Fig. 5), which contained GST by immunoblotting studies (data not shown). Presumably, because the molecular weight slightly exceeds that of GST alone ( $28 \mathrm{kD})$, a small fragment of the mutant spectrin peptide is likely preserved, attached to the GST.

The purified normal peptide sedimented with F-actin and protein 4.1 (Fig. 5, lane 2). There were increasing amounts of peptide sedimented with increasing peptide concentration, although saturation was not quite achieved, probably due to insufficient concentration of the peptide (data not shown). The nonspecific sedimentation of the peptide alone was minimal, in fact, undetectable at the lower concentrations (1-4 $\mu \mathrm{g}$ pep- 

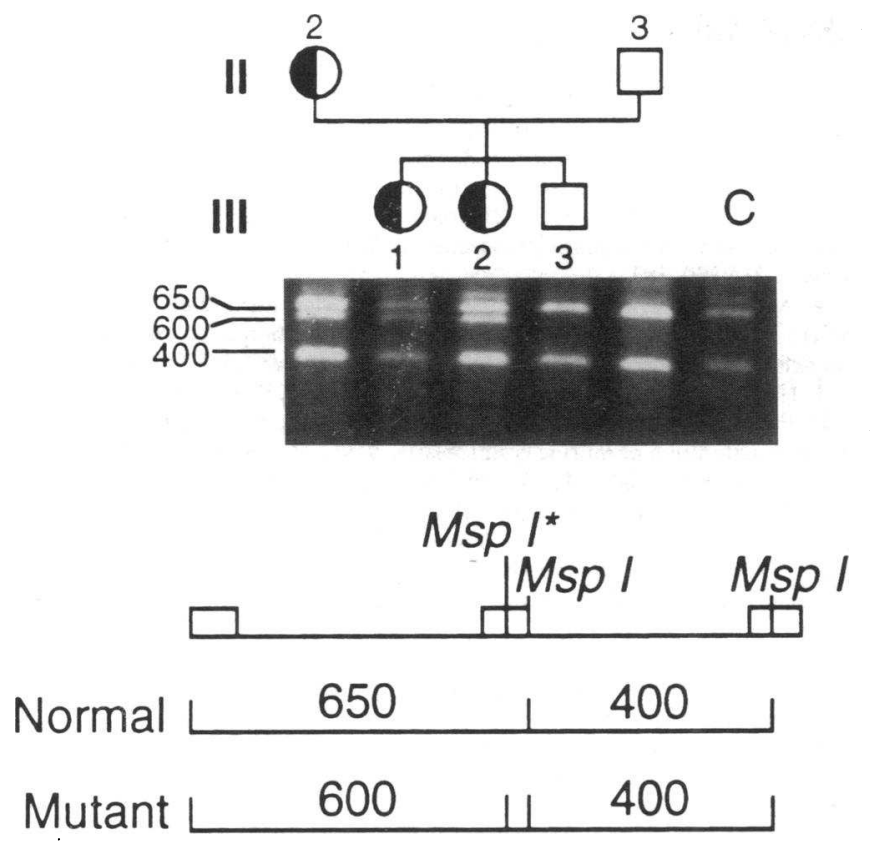

Figure 4. Restriction enzyme digestion with MspI. Genomic DNA was amplified by PCR using the primers $\mathrm{N} \beta 5$ and $\mathrm{N} \beta 7$ (AS). The open boxes denote the exons. With MspI digestion, the normal products are 650 and $400 \mathrm{bp}$. The asterisk indicates the MspI site that is created by the mutation and results in an extra product of $600 \mathrm{bp}$. Because the affected individuals are heterozygous, both the 650 and $600 \mathrm{bp}$ products are seen in the patients.

tide). The peptide-actin binding was a fraction of the peptideactin-protein 4.1 binding. For example, for the highest input point, the amount of peptide sedimented with actin alone was $12.5 \%$ of the amount sedimented with both actin and protein 4.1. Because of the instability of the mutant peptide, its function could not be adequately assessed in vitro.

\section{Discussion}

Several actin-binding proteins share a homologous $\mathrm{NH}_{2}$-terminal domain, including $\beta$ spectrin, $\beta$ fodrin, $\alpha$ actinin, dystrophin, and other actin binding proteins (22-24). This region was found to contain the actin binding site, not only for erythrocyte spectrin, but also for the members of the spectrin gene

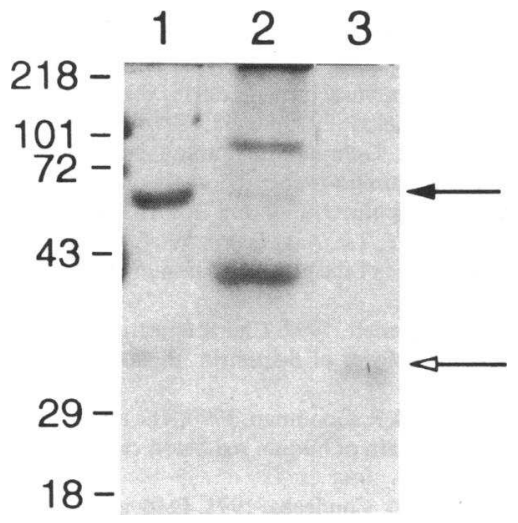

Figure 5. Recombinant $\mathrm{NH}_{2}$-terminal spectrin peptides. (Lane 1 ) the 64-kD recombinant peptide containing the GST (position indicated by the solid arrow) (Lane 2) the pellet obtained from a sedimentation assay containing protein 4.1 ( top band, $80 \mathrm{kD}$ ), the $64-\mathrm{kD}$ recombinant peptide (middle-band), and Factin (lower band, 42 kD). (Lane 3) the unstable mutant recombinant peptide degraded to $32 \mathrm{kD}$ (position indicated by the open arrow). The numerals to the left indicate the sizes of the molecular weight standards in $\mathrm{kD}$. superfamily as well. The binding site for actin was preserved within an erythroid $\beta$ spectrin peptide consisting of amino acids 47 to $186(25)$, or an even smaller 27 amino acid peptide highly conserved among $\alpha$ actinin, actin binding proteins, $\beta$ spectrin, dystrophin, and fimbrin (26).

The binding site for erythrocyte protein 4.1 has also been localized to this $\mathrm{NH}_{2}$-terminal region of $\beta$ spectrin (12), although because of the $16-\AA$ length of the cross-linker and the nature of the proteolytic techniques, the binding site could only be positioned somewhere within the entire $33 \mathrm{kD} \mathrm{NH}_{2}$-terminal domain. The kindred described in this report has a functional defect in roughly half of the spectrin dimers, which lack the capacity to bind protein $4.1(9)$. A single point mutation was found in codon 202 of $\beta$ spectrin cDNA, which at the protein level causes a change from the aromatic amino acid, tryptophan, to the positively charged amino acid, arginine. The location of this mutation is within a highly conserved region among members of the spectrin gene superfamily (Fig. 6). Overall, there is about $50 \%$ protein sequence homology among the spectrinlike proteins in the entire $\mathrm{NH}_{2}$-terminal region. Yet in the particular location of this mutation, there is even greater conservation of the sequence. For example, there is perfect conservation of the serine, an aromatic amino acid (tryptophan or phenylalanine in the case of two of the proteins), and the glycine and aspartic acid residues. There are only single cases of amino acid replacements of the lysine, arginine, and phenylalanine residues. The mutation replaces this perfectly conserved aromatic amino acid with a basic amino acid residue. Invariant tryptophans have previously been demonstrated to be highly conserved in other regions of spectrin (27). Moreover, there is a long sequence of hydrophobic amino acids to either side of the conserved tryptophan, with a charged pair consisting of lysine, positively charged, and aspartic acid, negatively charged, immediately adjacent to the tryptophan. It is intriguing that the negatively charged aspartic acid is perfectly conserved. The mutation adds an additional positively charged residue adjacent to the balanced charged pair. It is possible that this region represents the precise location of the protein 4.1 binding function, although this remains to be proven. This model would predict that the other members of the spectrin gene superfamily could bind protein 4.1 , and this is currently

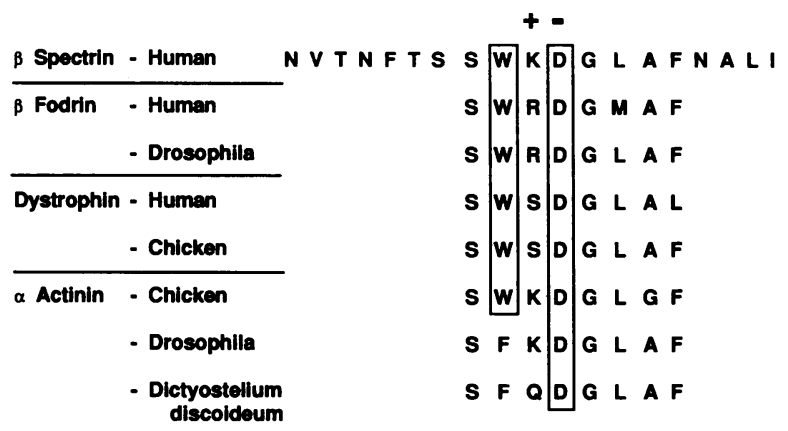

Figure 6. Conserved amino acid sequence among members of the spectrin gene superfamily. The amino acid sequence in the region of the mutation found in this kindred is well conserved. The boxes surround the tryptophans and the aspartic acids. The plus and minus indicate the position of the positive-negative,charged pair of amino acids. Note that the amino acids flanking the region of the charged pair are largely hydrophobic (23). The amino acid sequences were obtained from Byers et al. ([22] and references therein) for all proteins except human $\beta$ spectrin (23) and human beta fodrin (24). The mutation is tryptophan to arginine. 
under investigation. Moreover, protein 4.1 is found in numerous nonerythroid tissues, but its function and interactions with other cytoskeletal or membrane proteins are as of yet unknown.

Bacterial expression in the pGEX plasmid system of the mutant $\mathrm{cDNA}$ encoding the $\mathrm{NH}_{2}$-terminal region of $\beta$ spectrin resulted in an unstable, proteolytically degraded polypeptide. However, the normal recombinant peptide had preserved binding capacity for actin and protein 4.1. One cannot predict whether the mutant protein would be unstable in vivo on the basis of its instability in the bacterial expression system. However, it was found previously that the HS spectrin was more sensitive to oxidation (10). It is also interesting that there was a lower proportion of mutant spectrin isolated by protein 4.1 affinity chromatography (9) than would be predicted in a heterozygous individual ( 40 vs. $50 \%$ ), implying that there is indeed instability of the protein in vivo.

The mutation identified in this kindred apparently occurred as a spontaneous mutation in the proband, and was transmitted to two of her four children. RFLP analysis supported the paternity of the proband's father. The absolute relationship between the de novo occurrence of both the mutation and HS in the proband and transmission of both to two of the children suggests strongly that the mutation is the cause of the clinical disorder and the defective binding of protein 4.1 by the mutant $\beta$ spectrin. It is not known at present whether the acanthocytosis is also related to this $\beta$ spectrin defect. Because this mutation was spontaneous, it is not unreasonable that the examination by restriction enzyme digestion of amplified genomic DNA from the two other HS kindreds affected with a similar disorder on a protein level did not reveal an identical mutation. It is possible that they have mutations nearby that would be missed by restriction digestion with PvuII and MspI.

The majority of patients with HS do not have a defect in $\beta$ spectrin, but rather have abnormalities leading to deficiency of spectrin and/or ankyrin or band 3. It is currently unclear what proportion of HS cases have a defect in $\beta$ spectrin. However, due to the asymmetric synthetic ratio of $\alpha$ to $\beta$ spectrin, with assembly on the membrane dependent on the $\beta$ chain, one would predict that $\beta$ spectrin mutations would lead to autosomal dominant conditions. For example a point mutation in the $\mathrm{COOH}$-terminal region of $\beta$ spectrin associated with hereditary elliptocytosis (HE) was identifiable in the heterozygous state by ektacytometry and membrane fragmentation (18). In addition, the $\mathrm{COOH}$-terminal truncated $\beta$ spectrin chain variants are clinically affected with $\mathrm{HE}$ in the heterozygous state (For review, [1]). Thus, we report the first point mutation in autosomal dominant HS, located in $\beta$ spectrin, and predict that other defects of $\beta$ spectrin will be forthcoming in the future.

\section{Acknowledgments}

We are grateful to the generous cooperation in the donation of blood. samples on the part of all the patients and their family members. We are thankful to Mr. A. Scarpa for expert advice and technical instruction and to Ms. M. Doshi for skillful technical assistance in isolation and assay of recombinant proteins. We also acknowledge and thank Dr. B. Handelin of I. G. Laboratories for performing the paternity testing.

This work was supported in part by an institutional fellowship training grant (HL-07262) and grants to P. Becker (HL-02656), to B. Forget (DK-19842) and to S. Lux (DK-34083) from the National Institutes of Health, a Beginning Grant-In-Aid from the American Heart Association, Connecticut Affiliate, Inc. to P. Becker, and a March of Dimes Birth Defects Foundation fellowship to W. Tse.

\section{References}

1. Becker, P. S., and S. E. Lux. 1992. Disorders of the red cell membrane. In Hematology of Infancy and Childhood. 4th ed. D. G. Nathan and F. A. Oski, editors. W. B. Saunders Co., Philadelphia. 529-634.

2. Agre, P., E. P. Orringer, and V. Bennett. 1982. Deficient red-cell spectrin in severe, recessively inherited spherocytosis. N. Engl. J. Med. 306:1155-1161.

3. Agre, P., J. F. Casella, W. H. Zinkham, C. McMillan, and V. Bennett. 1985. Partial deficiency of erythrocyte spectrin in hereditary spherocytosis. Nature (Lond.). 314:380-383.

4. Agre, P., A. Asimos, J. F. Casella, and C. McMillan. 1986. Inheritance pattern and clinical response to splenectomy as a reflection of erythrocyte spectrin deficiency in hereditary spherocytosis. N. Engl. J. Med. 315:1579-1583.

5. Hanspal, M., J. S. Hanspal, R. Kairaiya, S.-C. Liu, K. E. Sahr, D. Howard, and J. Palek. 1992. Asynchronous synthesis of membrane skeletal proteins during terminal maturation of murine erythroblasts. Blood. 80:530-539.

6. Hanspal, M., and J. Palek. 1987. Synthesis and assembly of membrane skeletal proteins in mammalian red cell precursors. J. Cell Biol. 105:1417-1424.

7. Hanspal, M., S.-H. Yoon, H. Yu, J. S. Hanspal, S. Lambert, J. Palek, and J. T. Prchal. 1991. Molecular basis of spectrin and ankyrin deficiencies in severe hereditary spherocytosis: Evidence implicating a primary defect of ankyrin. Blood. 77:165-173.

8. Goodman, S. R., K. A. Shiffer, L. A. Casoria, and M. E. Eyster. 1982. Identification of the molecular defect in the erythrocyte membrane skeleton of some kindreds with hereditary spherocytosis. Blood. 60:772-784.

9. Wolfe, L. C., K. M. John, J. C. Falcone, A. M. Byrne, and S. E. Lux. 1982. A genetic defect in the binding of protein 4.1 to spectrin in a kindred with hereditary spherocytosis. N. Engl. J. Med. 307:1367-1374.

10. Becker, P. S., J. S. Morrow, and S. E. Lux. 1987. Abnormal oxidant sensitivity and $\beta$-chain structure of spectrin in hereditary spherocytosis associated with defective spectrin-protein 4.1 binding. J. Clin. Invest. 80:557-565.

11. Tyler, J. M., W. R. Hargreaves, and D. Branton. 1979. Purification of two spectrin-binding proteins: Biochemical and electron microscopic evidence for site-specific reassociation between spectrin and bands 2.1 and 4.1. Proc. Natl. Acad. Sci. USA. 76:5192-5196.

12. Becker, P. S., M. A. Schwartz, J. S. Morrow, and S. E. Lux. 1990. Radiolabel-transfer cross-linking demonstrates that protein 4.1 binds to the $\mathrm{N}$-terminal region of $\beta$ spectrin and to actin in binary interactions. Eur. J. Biochem. 193:827836.

13. Forget, B. G., J.-G. Chang, E. Coupal, P. Stanislovitis, F. F. Costa, J. C. Winkelmann, P. C. Agre, V. T. Marchesi, and P. C. Watkins. 1988. Molecular genetics of the human $\beta$-spectrin gene. Trans. Assoc. Am. Phys. 101:149-154.

14. Goossens, M., and Y. W. Kan. 1981. DNA analysis in the diagnosis of hemoglobin disorders. Methods Enzymol. 76:805-817.

15. Tse, W. T., P. G. Gallagher, B. Pothier, F. F. Costa, A. Scarpa, J. Delaunay, and B. G. Forget. 1991. An insertional frameshift mutation of the $\beta$-spectrin gene associated with elliptocytosis in spectrin Nice $\left(\beta^{220 / 216}\right)$. Blood. 78:517523.

16. Sanger, F., S. Nicklen, and A. R. Coulson. 1977. DNA sequencing with chain-terminating inhibitors. Proc. Natl. Acad. Sci. USA. 74:5463-5467.

17. Saiki, R. K., T. L. Bugawan, G. T. Horn, K. B. Mullis, and H. A. Erlich. 1986. Analysis of enzymatically amplified $\beta$-globin and HLA-DQ $\alpha$ DNA with allele-specific oligonucleotide probes. Nature (Lond.). 324:163-166.

18. Tse, W. T., M.-C. Lecomte, F. F. Costa, M. Garbarz, C. Feo, P. Boivin, D. Dhermy, and B. G. Forget. 1990. Point mutation in the $\beta$-spectrin gene associated with $\alpha \mathrm{I} / 74$ hereditary elliptocytosis. J. Clin. Invest. 86:909-916.

19. Smith, D. B., and K. S. Johnson. 1988. Single-step purification of polypeptides expressed in Escherichia coli as fusions with glutathione S-transferase. Gene (Amst.). 67:31-40.

20. Nagai, K., and H. C. Thogersen. 1984. Generation of $\beta$-globin by sequence-specific proteolysis of a hybrid protein produced in Escherichia coli. $\mathrm{Na}$ ture (Lond.). 309:810-812.

21. Laemmli, U. K. 1970. Cleavage of structural proteins during the assembly of the head of bacteriophage T4. Nature (Lond.). 227:680-685.

22. Byers, T. J., A. Husain-Chishti, R. R. Dubreuil, D. Branton, and L. S. B. Goldstein. 1989. Sequence similarity of the amino-terminal domain of Drosophila beta spectrin to alpha actinin and dystrophin. J. Cell Biol. 109:1633-1641.

23. Winkelmann, J. C., J.-G. Chang, W. T. Tse, A. L. Scarpa, V. T. Marchesi, and B. G. Forget. 1990. Full-length sequence of the cDNA for human erythroid $\beta$-spectrin. J. Biol. Chem. 265:11827-11832.

24. Hu, R.-J., M. Watanabe, and V. Bennett. 1992. Characterization of human brain cDNA encoding the general isoform of $\beta$-spectrin. J. Biol. Chem. 267:18715-18722.

25. Karinch, A. M., W. E. Zimmer, and S. R. Goodman. 1990. The identification and sequence of the actin-binding domain of human red blood cell $\beta$-spectrin. J. Biol. Chem. 265:11833-11840.

26. Bresnick, A. R., P. A. Janmey, and J. Condeelis. 1991. Evidence that a 27-residue sequence is the actin-binding site of ABP-120. J. Biol. Chem. 266:12989-12993.

27. Speicher, D. W., and V. T. Marchesi. 1984. Erythrocyte spectrin is comprised of many homologous triple helical segments. Nature (Lond.). 311:177180. 